\title{
Treatment Intensification for Locally Advanced Rectal Cancer: Impact on Pathological Complete Response and Outcomes
}

\author{
MONICA DI TOMMASO ${ }^{1}$, CONSUELO ROSA $^{1}$, LUCIANA CARAVATTA ${ }^{1}$, ANTONIETTA AUGURIO ${ }^{1}$, \\ VALENTINA BORZILLO ${ }^{2}$, SARA DI SANTO ${ }^{1}$, FRANCESCA PERROTTI ${ }^{1}$, MARIA TARABORRELLI ${ }^{1}$, \\ ROBERTA CIANCI $^{3}$, PAOLO INNOCENTI ${ }^{4}$, PIERLUIGI DI SEBASTIANO ${ }^{5}$, \\ ANTONELLA COLASANTE ${ }^{6}$, DOMENICO ANGELUCCI ${ }^{6}$, MASSIMO BASTI $^{7}$, GIULIA SINDICI $^{8}$, \\ LORENZO MAZZOLA ${ }^{9}$, GIUSEPPE PIZZICANNELLA ${ }^{10}$, NICOLA DI BARTOLOMEO ${ }^{4}$, \\ MICHELE MARCHIONI ${ }^{11}$, MARTA DI NICOLA ${ }^{11}$ and DOMENICO GENOVESI ${ }^{1}$ \\ ${ }^{1}$ Department of Radiation Oncology, SS. Annunziata Hospital, G. D'Annunzio University, Chieti, Italy; \\ ${ }^{2}$ Department of Radiation Therapy, Istituto Nazionale Tumori-IRCCS-Fondazione G. Pascale, Naples, Italy; \\ ${ }^{3}$ Department of Radiology, SS. Annunziata Hospital, G. D'Annunzio University, Chieti, Italy; \\ ${ }^{4}$ Division of Surgery, Villa Serena Clinic, Città S. Angelo, Italy; \\ ${ }^{5}$ Department of Medical and Oral Sciences and Biotechnologies, G. D'Annunzio University, Chieti, Italy; \\ ${ }^{6}$ Division of Pathology, SS. Annunziata Hospital, Chieti, Italy; \\ ${ }^{7}$ Division of Surgery III, Santo Spirito Hospital, Pescara, Italy; \\ ${ }^{8}$ Division of Pathology, Santo Spirito Hospital, Pescara, Italy; \\ ${ }^{9}$ Division of Surgery, Renzetti Hospital, Lanciano, Italy; \\ ${ }^{10}$ Division of Pathology, Villa Serena Clinic, Città S. Angelo, Italy; \\ ${ }^{11}$ Laboratory of Biostatistics, Department of Medical, Oral and Biotechnological Sciences, \\ G. D'Annunzio University, Chieti, Italy
}

\begin{abstract}
Aim: Pathological complete response ( $p C R)$ and clinical outcomes [overall survival (OS), disease-free survival (DFS), locoregional control (LC)] were evaluated in a single-institution experience of different schedules of neoadjuvant chemoradiotherapy (CRT) for patients with locally advanced rectal cancer (LARC). Patients and Methods: Data for 322 patients with LARC were retrospectively analyzed. $p C R$ was evaluated according to Mandard tumor regression grade (TRG). The Kaplan-Meier method was used to estimate OS, DFS and LC. Results: Three hundred and three (94.1\%) patients underwent surgery. $p C R$ was observed in 81 patients (26.7\%), with TRG1-2 rate of $41.8 \%$. The 5- and 10-year OS, DFS and LC rates were $82.5 \% \pm 2.5 \%$ and $65.5 \% \pm 3.8 \%, 81.2 \% \pm 2.4 \%$ and
\end{abstract}

This article is freely accessible online.

Correspondence to: Luciana Caravatta, Department of Radiation Oncology, SS Annunziata Hospital, Via Dei Vestini, 66100 Chieti, Italy. Tel: +39 0871358244, Fax: +39 08713557374, e-mail: lcaravatta@hotmail.com

Key Words: Chemoradiotherapy, late toxicities, long-term results, rectal cancer, pathological complete response.
$79.3 \% \pm 2.9 \%, 93.1 \% \pm 1.7 \%$ and $90.5 \% \pm 2.1 \%$, respectively. Conclusion: Neoadjuvant CRT in LARC patients resulted in favorable long-term oncological outcomes, with a high $p C R$ rate and acceptable toxicity.

Preoperative long-course chemoradiotherapy (CRT) followed by total mesorectal excision (TME) for stage II/III rectal cancer is effective in reducing tumor size, increasing tumor resectability probability and allowing sphincter-saving surgery, with an improvement in the locoregional control (LC) rate $(1,2)$. In addition, an increased rate of pathological complete response (pCR, i.e. the absence of pathological cells in surgical resection) was reported in about $12-15 \%$ of patients treated with concurrent fluoropyrimidine $(3,4)$. Oral capecitabine represents a therapy option and is as welltolerated, nontoxic and effective in down-staging as 5fluorouracil for neoadjuvant treatment for locally advanced rectal cancer (LARC) (5-7). Aiming to improve clinical outcomes, during the past two decades, many studies have been conducted to evaluate the impact of treatment intensification in terms of dose escalation or drug combination, with differing results.

Following this evidence, different schedules of CRT have also been utilized at Department of Radiation Oncology of Chieti. We retrospectively analyzed data of patients treated 
with neoadjuvant long-course CRT, dividing patients into subgroups according to the different CRT schedules used. We evaluated pCR, and long-term oncological outcomes such as rates of overall (OS) and disease-free (DFS) survival, and LC, estimating factors associated with oncological outcomes.

\section{Patients and Methods}

From 2001 to 2019, 322 patients with LARC were treated with preoperative CRT at Department of Radiation Oncology of Chieti and retrospectively analyzed. All patients had histologically confirmed primary adenocarcinoma of the rectum, without extra pelvic disease and staged as cT2-4 N0-2, according to the tumor node metastasis (TNM) staging system (8).

Baseline staging and re-staging after CRT were performed with digital rectal examination and chest-abdominal-pelvic computed tomography (CT) scans, with or without a rectal magnetic resonance imaging (MRI) at least 4 weeks after the end of CRT. RT was performed by $3 \mathrm{D}$ conformal technique, with a total dose of 4,500 cGy, $180 \mathrm{cGy} /$ day, to the pelvic nodes, followed by a sequential boost of $540 \mathrm{cGy}$ (180 cGy/day; total dose 5,040 cGy), or a concomitant boost of $1,000 \mathrm{cGy}(100 \mathrm{cGy} /$ day, 2 times/week; total dose 5,500 cGy) initially with a 3D-CRT technique and then with simultaneous integrated boost with intensity-modulated radiotherapy (220 cGy/day, total dose $5500 \mathrm{cGy}$ ).

During the simulation process, patients were immobilized in the prone position on a belly board, a device aimed at reducing small bowel irradiation, or in the supine position for simultaneous integrated boost with intensity-modulated radiotherapy procedure. The clinical target volume (CTV) included the primary tumor as well as mesorectum, pre-sacral and pelvic nodes up to the L5/S1 junction. In lateral fields, the entire sacrum was included, and the anterior border included the posterior part of the prostate or vagina. Subsequently, the CTV was delineated according to the guidelines available in 2006, including the primary tumor, mesorectum and pelvic subsites (9). The planning target volume (PTV) was the CTV plus $1 \mathrm{~cm}$ margin in all directions. Dose was specified according to the International Commission on Radiation Units and Measurements Report 50-62 (10).

Different schedules of drugs were administered as concomitant chemotherapy: 5-Fluorouracil (5-FU) and leucovorin (750-1,000 $\mathrm{mg} / \mathrm{m}^{2}$, continuous infusion from 4 to 5 days) or capecitabine (825 $\mathrm{mg} / \mathrm{m}^{2}$, twice a day for 7 days/week), alone or in association with cisplatin (Plafur: $60 \mathrm{mg} / \mathrm{m}^{2}$, days 1 and 29, and a 24-h continuous intravenous infusion of $5-\mathrm{FU}$ at $1,000 \mathrm{mg} / \mathrm{m}^{2}$, days $1-4$ and 29-32) or oxaliplatin (Capeox: capecitabine at $1,300 \mathrm{mg} / \mathrm{m}^{2} /$ day, three times/day, for 7 days/week and oxaliplatin at $130 \mathrm{mg} / \mathrm{m}^{2}$, days 1,19 and 38). In addition, in patients enrolled in an Italian trial, oxaliplatin was associated with raltitrexed (Tomox: intravenous infusion of raltitrexed at $3 \mathrm{mg} / \mathrm{m}^{2}$, and oxaliplatin at $130 \mathrm{mg} / \mathrm{m}^{2}, 20 \mathrm{~min}$ after raltitrexed as a 2-h intravenous infusion, on days 1,17 and 35) $(11,12)$.

According to different RT doses and chemotherapy schedules used, we divided our populations into four groups: Fluoropyrimidine chemotherapy plus 50 Gy (fluoropyrimidine group), Plafur chemotherapy plus 50 Gy (Plafur group), Tomox-Capox chemotherapy plus 50 Gy (Tomox-Capox group) and capecitabine with a dose escalation up to 55 Gy corresponding to an equivalent dose at $2 \mathrm{~Gy} /$ fraction (EQD2) of $57.5 \mathrm{~Gy}$ (considering $\alpha / \beta=5.06 \mathrm{~Gy}$ for rectal tumor) (dose intensification group). Radical surgery, including TME, and abdominoperineal resection (APR) or anterior resection, with colorectal or colon-anal anastomosis, was performed according to surgical evaluation.

Considering the distance between the lower pole of the tumor from the anorectal ring, as reported at diagnostic work-up, our patients were split into three subgroups to evaluate possible surgical procedure: Very low location when the distance was $<30 \mathrm{~mm}$ (candidates for an APR procedure); low location when the distance was 31-50 mm (potential candidates for an APR procedure); and mid-high location when the distance was $>50 \mathrm{~mm}$ (candidates for a sphincter-saving procedure) (13).

The pathological response was evaluated according to the pTNM pathological classification of the Union for International Cancer Control (8) and tumor regression grade (TRG), based on the Mandard score (14). Tumor regression was classified according to five grades, TRG1 to TRG5, from the best response to the worst, respectively. The absence of residual cancer in the resected specimen (TRG 1) was defined as pCR.

Adjuvant chemotherapy was recommended for patients with positive nodes at pathological examination and for those with T3-4 tumors.

Radiation Therapy Oncology Group (RTOG) toxicity criteria were used to score acute RT toxicities (15). Postoperative routine follow-up examinations were performed every 6 months during the first 5 years from surgery, then annually. Gastrointestinal symptoms and anorectal function of patients were evaluated at baseline and at every follow-up examination. Late toxicities were reported according to the RTOG/European Organization for Research and Treatment of Cancer (EORTC) late RT scoring system (16).

Statistical analysis. All qualitative variables were summarized as frequencies and percentages, whereas all quantitative variables were summarized as the means and standard deviation (SD) or median and interquartile range (IQR) according to their distribution, following the Shapiro-Wilk test.

The Kaplan-Meier method (17) was used to calculate the 5- and 10-year rates of OS, DFS and LC. The follow-up was defined as the time interval between surgery and death due to disease or, for the DFS curve, as the time between surgery and the first verified event; and as the time between surgery and the locoregional recurrence for the LC curve. For patients in whom none of the events occurred, the observational time interval was defined as the period from surgery to the last follow-up visit.

The Kaplan-Meier method was also used to estimate OS, DFS and LC at 5 and 10 years of follow-up after stratifying patients for all other factors. Statistical significance between curves was evaluated using the log-rank test.

A $p$-value of 0.05 or less was considered statistically significant. All statistical analyses were performed using SPSS ${ }^{\circledR}$ software 11.0 (SPSS Inc., Chicago, IL, USA). All research was performed in accordance with the actual version of declaration of Helsinki. No further ethical approval was necessary because this retrospective study was anonymous and non interventional.

\section{Results}

Patient population, treatment compliance and acute toxicity. A total of 322 patients were analyzed in this study. Patients, tumor and treatment characteristics are shown in Table I. The median patient age was 65.5 years (range=32-88 years); $209(64.9 \%)$ patients were male. Most patients (80.8\%) had cT3 tumors. 
Table I. Tumor, patients and treatment characteristics $(n=322)$.

\begin{tabular}{|c|c|c|}
\hline Characteristic & & Value \\
\hline Age, years & Median (range) & $65.5(32-88)$ \\
\hline \multirow[t]{2}{*}{ Gender, n (\%) } & Male & $209(64.9 \%)$ \\
\hline & Female & $113(35.1 \%)$ \\
\hline \multirow[t]{3}{*}{ Clinical T-stage, n (\%) } & $\mathrm{T} 2$ & $33(10.2 \%)$ \\
\hline & $\mathrm{T} 3$ & $260(80.8 \%)$ \\
\hline & $\mathrm{T} 4$ & $29(9 \%)$ \\
\hline \multirow[t]{3}{*}{ Clinical N-stage, n (\%) } & No & $83(25.8 \%)$ \\
\hline & N1 & $156(48.4 \%)$ \\
\hline & N2 & $83(25.8 \%)$ \\
\hline \multirow[t]{5}{*}{ Grade, n (\%) } & 1 & $42(13 \%)$ \\
\hline & 2 & $195(60.6 \%)$ \\
\hline & 3 & $20(6.2 \%)$ \\
\hline & NOS & $23(6.8 \%)$ \\
\hline & Unknown & $44(13.4 \%)$ \\
\hline Tumor length, mm & Median (range) & $50(6-130)$ \\
\hline \multirow{4}{*}{$\begin{array}{l}\text { Distance from anorectal } \\
\text { ring, } \mathrm{mm}\end{array}$} & $0-30$ & $98(30.4 \%)$ \\
\hline & $31-50$ & $92(28.6 \%)$ \\
\hline & $>50$ & $107(33.2 \%)$ \\
\hline & Unknown & $25(7.8 \%)$ \\
\hline \multirow[t]{5}{*}{ Chemotherapy schedule } & Fluoropyrimidine & $54(16.8 \%)$ \\
\hline & $+45-50$ Gy & \\
\hline & Plafur+50 Gy & $138(42.8 \%)$ \\
\hline & Tomox-Capeox+50 Gy & $25(7.8 \%)$ \\
\hline & Capecitabine+>50 Gy & $105(32.6 \%)$ \\
\hline \multirow[t]{6}{*}{ Type of surgery } & TEM & $9(2.8 \%)$ \\
\hline & $\mathrm{AR}$ & $230(71.5 \%)$ \\
\hline & APR & $55(17 \%)$ \\
\hline & Other & $9(2.8 \%)$ \\
\hline & None & $10(3.1 \%)$ \\
\hline & Unknown & $9(2.8 \%)$ \\
\hline \multirow[t]{3}{*}{ Margin status* } & R0 & $226(74.6 \%)$ \\
\hline & $\mathrm{R} 1$ & $4(1.3 \%)$ \\
\hline & Unknown & $73(24.1 \%)$ \\
\hline \multirow[t]{5}{*}{ Pathological T-stage* } & T0 & $72(23.8 \%)$ \\
\hline & $\mathrm{T} 1$ & $31(10.2 \%)$ \\
\hline & $\mathrm{T} 2$ & $90(29.7 \%)$ \\
\hline & $\mathrm{T} 3$ & $106(35.0 \%)$ \\
\hline & $\mathrm{T} 4$ & $4(1.3 \%)$ \\
\hline \multirow[t]{3}{*}{ Pathological N-stage* } & No & $245(80.9 \%)$ \\
\hline & N1 & $46(15.2 \%)$ \\
\hline & $\mathrm{N} 2$ & $12(3.9 \%)$ \\
\hline \multirow[t]{6}{*}{ TRG* } & 1 & $81(26.7 \%)$ \\
\hline & 2 & $46(15.1 \%)$ \\
\hline & 3 & $100(33 \%)$ \\
\hline & 4 & $69(22.8 \%)$ \\
\hline & 5 & $5(1.7 \%)$ \\
\hline & Unknown & $2(0.7 \%)$ \\
\hline
\end{tabular}

Plafur: Cisplatin and 5-fluorouracil; Tomox: raltitrexed and oxaliplatin; Capeox: capecitabine and oxaliplatin; TEM: transanal endoscopic microsurgery; AR: anterior resection; APR: abdominal peritoneal resection; R0: absence of tumor cells in resection margin; R1: tumor cells in resection margin; TRG: tumor resection grade; NOS: not otherwise specified; SD: standard deviation. $* \mathrm{~N}=303$.
Table II. Clinical and pathological stages and type of surgery according to chemoradiotherapy (CRT) regimen.

\begin{tabular}{|c|c|c|c|c|}
\hline & \multicolumn{4}{|c|}{ CRT regimen, $\mathrm{n}$} \\
\hline & Fluoropyrimidine & Plafur & $\begin{array}{l}\text { Tomox- } \\
\text { Capeox }\end{array}$ & $\begin{array}{c}\text { Dose } \\
\text { intensification }\end{array}$ \\
\hline \multicolumn{5}{|c|}{$\begin{array}{l}\text { Clinical stage } \\
\text { pre-CRT } \\
(n=322)\end{array}$} \\
\hline I & 3 & 0 & 0 & 1 \\
\hline IIA & 17 & 32 & 5 & 19 \\
\hline IIB & 1 & 3 & 0 & 2 \\
\hline IIIA & 4 & 12 & 2 & 3 \\
\hline IIIB & 25 & 51 & 14 & 49 \\
\hline IIIC & 4 & 40 & 4 & 31 \\
\hline \multicolumn{5}{|c|}{ Surgery $(n=303)$} \\
\hline TEM & 1 & 2 & 0 & 6 \\
\hline $\mathrm{AR}$ & 29 & 107 & 19 & 77 \\
\hline APR & 14 & 24 & 5 & 10 \\
\hline Other & 2 & 3 & 0 & 4 \\
\hline \multicolumn{5}{|c|}{$\begin{array}{l}\text { Pathological } \\
\text { stage }(\mathrm{n}=303)^{*}\end{array}$} \\
\hline ypT0N0 & 10 & 17 & 9 & 36 \\
\hline ypT0N1 & 0 & 2 & 0 & 0 \\
\hline 0 & 0 & 0 & 0 & 1 \\
\hline I & 17 & 49 & 12 & 29 \\
\hline IIA & 13 & 35 & 1 & 13 \\
\hline IIB & 0 & 2 & 2 & 0 \\
\hline IIC & 0 & 1 & 0 & 0 \\
\hline IIIA & 1 & 4 & 0 & 6 \\
\hline IIIB & 3 & 18 & 0 & 10 \\
\hline IIIC & 2 & 8 & 0 & 2 \\
\hline
\end{tabular}

CRT: Chemoradiotherapy; Plafur: cisplatin and 5-fluorouracil; Tomox: raltitrexed and oxaliplatin; Capeox: capecitabine and oxaliplatin; TEM: transanal endoscopic microsurgery; AR: anterior resection; APR: abdominal peritoneal resection. *According to TNM fifth edition (8).

The majority of patients $(139,43.2 \%)$ presented disease of TNM-Union for International Cancer Control stage IIIB, followed by $79(24.5 \%)$ with stage IIIC and $73(22.7 \%)$ with stage IIA. Only $21(6.6 \%)$ patients presented with disease in stage IIIA, four (1.2\%) in stage I and four (1.2\%) in stage IIB and two $(0.6 \%)$ stage IIC.

Median tumor length was $50 \mathrm{~mm}$, sited at a distance from the anorectal ring less than $30 \mathrm{~mm}$, between 31 and $50 \mathrm{~mm}$ and more than $50 \mathrm{~mm}$ in 98 (30.4\%), 92 (28.6\%) and 107 (33.2\%) patients, respectively. Our analysis was conducted on 54 (16.8\%) patients in the fluoropyrimidine group, $138(42.8 \%)$ in the Plafur group, 25 (7.8\%) in the Tomox-Capeox group and $105(32.6 \%)$ patients in the dose intensification group.

Lower gastrointestinal toxicity was the most frequent acute side-effect experienced: 215 patients $(67.7 \%)$ had grade 1-2 toxicity, whereas 13 patients experienced grade 3 $(4 \%)$, as rectal bleeding/severe diarrhea, with one patient $(1.9 \%)$ in the fluoropyrimidine group, $10(7.2 \%)$ in the 
in vivo $34: 1223-1233(2020)$

Table III. Logistic regression predicting tumor resection grade (TRG) 1-2 vs. TRG 3-5.

\begin{tabular}{|c|c|c|c|c|}
\hline Therapy arm & TRG $1-2, \mathrm{n}(\%)$ & TRG 3-5, n (\%) & $\begin{array}{c}\text { Odds ratio ( } 95 \% \\
\text { confidence interval) }\end{array}$ & $p$-Value \\
\hline Fluoropyrimidine & $19(42.2)$ & $26(57.8)$ & Reference & - \\
\hline Plafur & $38(27.9)$ & $98(72.1)$ & $0.53(0.26-1.07)$ & 0.076 \\
\hline Tomox-Capeox & $13(54.2)$ & $11(45.8)$ & $1.61(0.59-4.40)$ & 0.345 \\
\hline Dose intensification & $57(59.4)$ & 39 (40.6) & $2.09(1.01-4.33)$ & 0.046 \\
\hline
\end{tabular}

Plafur: Cisplatin and 5-fluorouracil; Tomox: raltitrexed and oxaliplatin; Capeox: capecitabine and oxaliplatin.

Plafur group and $2(1.9 \%)$ in the dose intensification group. Skin (humid exfoliation), genitourinary (hematuria) and hematological (anemia) grade 3 toxicities were reported in $11(3.4 \%)$, seven $(2.2 \%)$ and four $(1.2 \%)$ patients, respectively. Major acute adverse events occurred in the Plafur group: Nine out of 11 patient $(6.5 \%)$ experienced skin toxicity, six out of $7(4.3 \%)$ had genitourinary toxicity and three out of four $(2.2 \%)$ patients had hematological grade 3 toxicity. Eight patients $(2.5 \%)$ had more than a 10 -day break in treatment due to severe toxicities. There were no reported severe neurological and liver toxicities.

Surgery, downstaging and pathologicaI response. Three hundred and three $(94.1 \%)$ patients underwent surgery.

Anterior resection was performed in 230 patients $(71.5 \%)$ and APR in $55(17 \%)$ patients. Nine patients $(2.8 \%)$ with favorable clinical stage (cT2N0) and major pathological response underwent trans-anal endoscopic microsurgery, whereas two patients did not undergo surgery due to their good response observed at the pre-operative re-evaluation. Other surgical techniques were performed in nine $(2.8 \%)$ patients. Eight $(2.5 \%)$ patients did not undergo surgery due to being clinically unfit for surgical procedures, or rejection. Data regarding type of surgery were missing for nine $(2.8 \%)$ patients. Sphincter-saving surgery was possible in $53.7 \%$ (29 patients) for the fluoropyrimidine group, $77.5 \%$ (107 patients) of the Plafur group and $73.3 \%$ (77 patients) for the dose intensification group (Table II).

Sphincter-saving procedure, according to the distance between the lower pole of the tumor and the anorectal ring, was achieved in 60 patients out of $98(61.2 \%)$ in the very low tumor group, 78 out of $92(84.8 \%)$ in the low tumor group, and 83 out of $108(76.9 \%)$ in the mid-high tumor group.

Tumor and nodal-status down-staging was detected in 192 out of 303 patients $(63.4 \%)$ and in 263 out of 303 patients $(86.8 \%)$, respectively. Detailed post-neoadjuvant treatment and pathological stages are shown in Table II.

The primary endpoint was the TRG rate: TRG1 was obtained in $81(26.7 \%)$ patients, TGR2 in $46(15.1 \%)$, TRG3 in $100(33.0 \%)$, TRG4 in $69(22.8 \%)$ and TRG5 in five
$(1.7 \%)$ patients; data were missing for two patients $(0.7 \%)$. Overall, the major pathological response (TRG1-2) rate was $41.8 \%$. The proportion of patients with a TRG1-2 was higher in the dose intensification arm (57 patients, 59.4\%) compared to the fluoropyrimidine arm (19 patients, $42.2 \%)$, Plafur arm (38 patients, 27.9\%) and Tomox-Capeox arm (13 patients, $54.2 \%$ ), with a statistical significance difference in the dose intensification group ( $p=0.046)$ (Table III).

Adjuvant chemotherapy was performed in 89 (30.7\%) patients: Systemic fluoropyrimidine-based chemotherapy in $51(57.3 \%)$ and intensification with oxaliplatin in the remaining $38(42.7 \%)$.

Late toxicity and outcomes. The median follow-up was 67.3 months (IQR=34.8-109.6 months). According to the RTOG/EORTC scale, late bowel dysfunction in terms of bleeding requiring surgery (G3 toxicity) was reported in eight patients $(2.4 \%$ ). Mild (five daily bowel movements) and moderate (more than five daily bowel movements) diarrhea were reported in $59(20.4 \%)$ and $25(8.7 \%)$ patients, respectively. No other severe late toxicities were recorded, except for two $(0.6 \%)$ patients with severe dysuria and one $(0.3 \%)$ case with gross telangiectasia.

The 5-year OS, DFS and LC rates were $82.5 \% \pm 2.5 \%$, $81.2 \% \pm 2.4 \%$ and $93.1 \% \pm 1.7 \%$, respectively. Long-term results at 10 years showed OS, DFS and LC rates of $65.5 \% \pm 3.8 \%, 79.3 \% \pm 2.9 \%$, and $90.5 \% \pm 2.1 \%$, respectively (Figure 1). OS, DFS and LC rates were not statistically different between the four treatment groups.

Figure 2 shows the 5- and 10-year OS, DFS and LC for patients with TRG1-2 and with TRG3-5. Patients with TRG1-2 had significantly better OS, with 5- and 10-year rates of $85.7 \%( \pm 3.7 \%)$ and $84.2 \%( \pm 3.9 \%)$ compared with $80.1 \%( \pm 3.2 \%)$ and $56.3 \%( \pm 5.0 \%)$, respectively, for patients with TRG3-5 $(p=0.001)$. The 5- and 10-year DFS rates for patients with TRG1-2 were similarly better at $89.5 \%( \pm 3.2 \%)$ and $87.7 \%( \pm 3.6 \%)$ compared with $80.2 \%( \pm 3.4 \%)$ and $73.6 \%( \pm 4.1 \%)$, respectively, for patients with TRG3-5 $(p=0.014)$. The 5- and 10-year LC rates for patients with TRG1-2 were $93.5 \%( \pm 2.6 \%)$ and $91.9 \%( \pm 2.9 \%)$ and did not significantly differ from those with TRG3-5 (Table IV). 

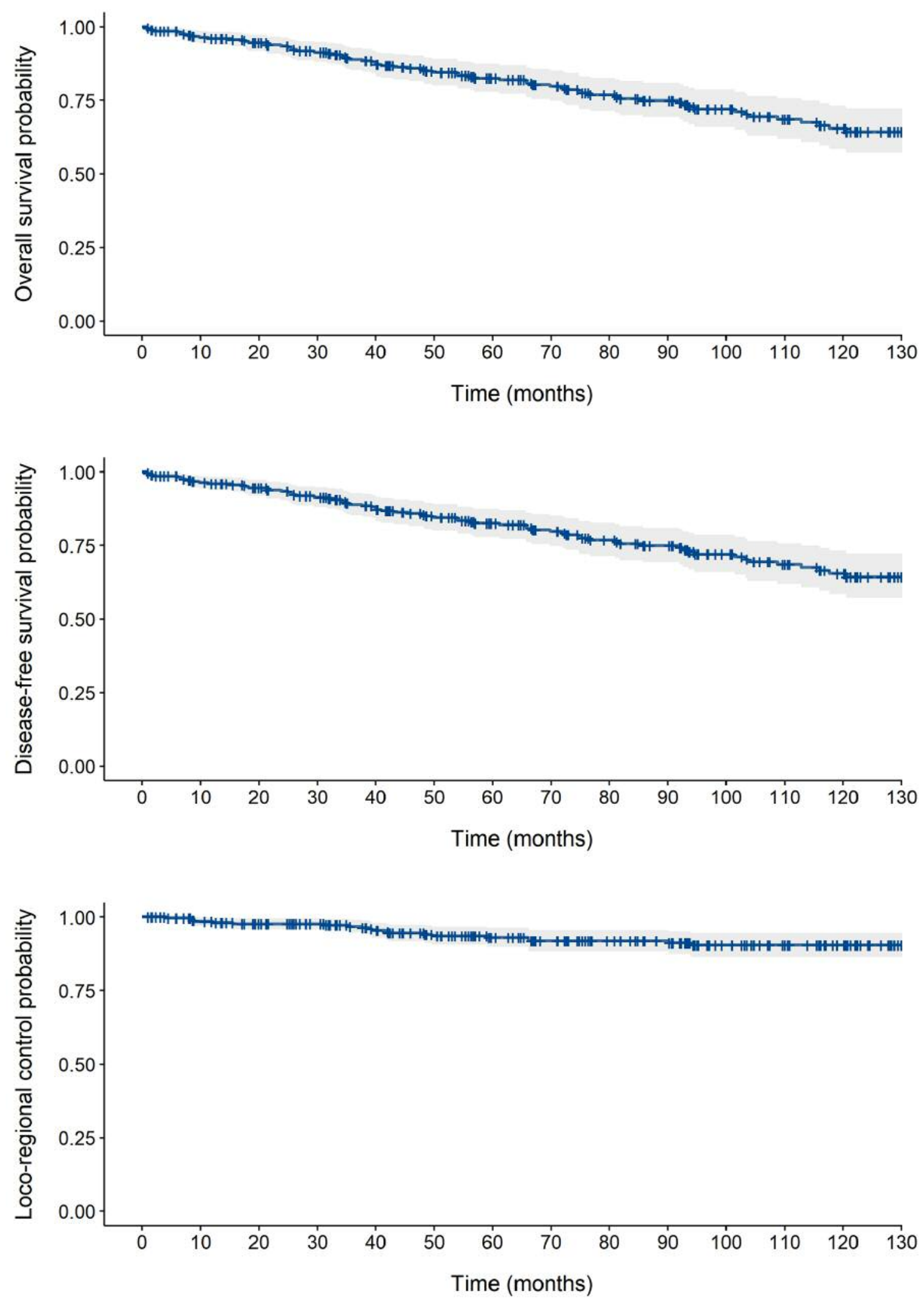

Figure 1. Kaplan-Meier curves of cumulative overall (A) and (B) disease-free survival as well as locoregional control (C). Tick marks represent cases lost to follow-up and the grey region represents the $95 \%$ confidence interval. 

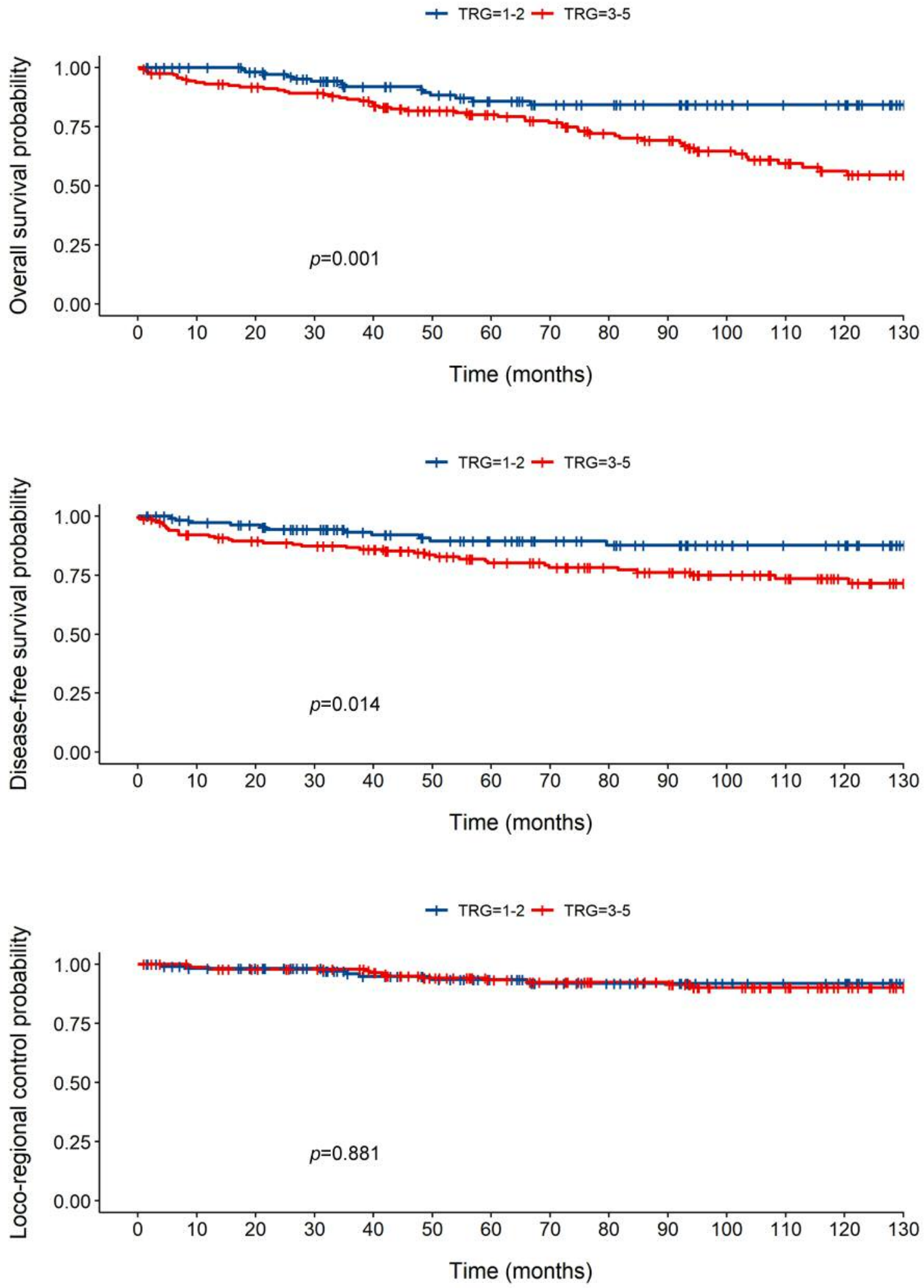

Figure 2. Kaplan-Meier curves of cumulative overall $(A)$ and $(B)$ disease-free survival as well as locoregional control $(C)$ for patients with tumor regression grade (TRG) 1-2 and those with TRG 3-5. Tick marks represent cases lost to follow-up and the grey region represents the $95 \%$ confidence interval. 
Table IV. Clinical outcomes at 5 and 10 years according to tumor regression grade (TRG) and treatment and tumor parameters.

\begin{tabular}{|c|c|c|c|c|c|c|c|c|c|c|c|c|}
\hline & \multicolumn{4}{|c|}{ OS } & \multicolumn{4}{|c|}{ DFS } & \multicolumn{4}{|c|}{$\mathrm{LC}$} \\
\hline & \multicolumn{2}{|c|}{ Rate \pm SE, $\%$} & \multirow[b]{2}{*}{ HR $(95 \%$ CI $)$} & \multirow[b]{2}{*}{$p$-Value } & \multicolumn{2}{|c|}{ Rate \pm SE, $\%$} & \multirow[b]{2}{*}{ HR $(95 \%$ CI $)$} & \multirow[b]{2}{*}{$p$-Value } & \multicolumn{2}{|c|}{ Rate \pm SE, $\%$} & \multirow[b]{2}{*}{ HR $(95 \%$ CI $)$} & \multirow[b]{2}{*}{$p$-Value } \\
\hline & 5 Years & 10 Years & & & 5 Years & 10 Years & & & 5 Years & 10 Years & & \\
\hline Overall & $82.5 \pm 2.5$ & $65.5 \pm 3.8$ & - & - & $84.2 \pm 2.4$ & $79.3 \pm 2.9$ & - & - & $93.1 \pm 1.7$ & $90.5 \pm 2.1$ & - & - \\
\hline \multicolumn{13}{|c|}{$\begin{array}{l}\text { Anorectal } \\
\text { ring distance }\end{array}$} \\
\hline $0-30 \mathrm{~mm}$ & $86.0 \pm 4.1$ & $58.1 \pm 7.4$ & Reference & & $77.4 \pm 5.2$ & $66.7 \pm 6.8$ & Reference & & $92.7 \pm 3.2$ & $92.7 \pm 3.2$ & Reference & \\
\hline $31-50 \mathrm{~mm}$ & $75.1 \pm 5.0$ & $64.9 \pm 6.1$ & $1.02(0.6-1.8)$ & 0.940 & $87.8 \pm 3.9$ & $83.4 \pm 4.8$ & $0.5(0.2-1.0)$ & 0.051 & $93.8 \pm 3.0$ & $87.4 \pm 4.6$ & $1.2(0.4-3.8)$ & 0.746 \\
\hline$\geq 51 \mathrm{~mm}$ & $87.3 \pm 3.8$ & $74.2 \pm 6.2$ & $0.6(0.3-1.1)$ & 0.094 & $88.1 \pm 3.6$ & $86.2 \pm 4.0$ & $0.5(0.2-0.9)$ & 0.037 & $93.9 \pm 2.7$ & $92.3 \pm 3.1$ & $0.9(0.3-3.1)$ & 0.914 \\
\hline \multicolumn{13}{|l|}{ TRG } \\
\hline $1-2$ & $85.7 \pm 3.7$ & $84.2 \pm 3.9$ & Reference & & $89.5 \pm 3.2$ & $87.7 \pm 3.6$ & Reference & & $93.5 \pm 2.6$ & $91.9 \pm 2.9$ & Reference & \\
\hline $3-5$ & $80.1 \pm 3.2$ & $56.3 \pm 5.0$ & $2.7(1.5-4.8)$ & 0.001 & $80.2 \pm 3.4$ & $73.6 \pm 4.1$ & $2.3(1.2-4.3)$ & 0.014 & $93.4 \pm 2.2$ & $90.2 \pm 2.8$ & $1.1(0.4-2.7)$ & 0.881 \\
\hline \multicolumn{13}{|c|}{ 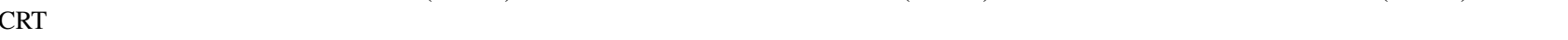 } \\
\hline $\begin{array}{l}\text { Fluoropy- } \\
\text { rimidine }\end{array}$ & $77.5 \pm 7.6$ & $47.9 \pm 13.8$ & Reference & & $90.0 \pm 5.5$ & $90.0 \pm 5.5$ & Reference & & $96.9 \pm 3.1$ & $91.8 \pm 5.8$ & Reference & \\
\hline Plafur & $80.8 \pm 3.4$ & $64.6 \pm 4.3$ & $0.8(0.4-1.6)$ & 0.532 & $81.8 \pm 3.4$ & $76.4 \pm 8.3$ & $2.2(0.7-7.3)$ & 0.187 & $94.6 \pm 2.0$ & $91.9 \pm 2.5$ & $0.9(0.2-4.4)$ & 0.951 \\
\hline $\begin{array}{l}\text { Tomox- } \\
\text { Capeox }\end{array}$ & $95.0 \pm 4.9$ & $95.0 \pm 4.9$ & $0.2(0.02-1.3)$ & 0.082 & $87.7 \pm 8.3$ & $87.7 \pm 8.3$ & $1.1(0.2-6.4)$ & 0.951 & $94.4 \pm 5.4$ & $94.4 \pm 5.4$ & $0.8(0.1-8.8)$ & 0.853 \\
\hline $\begin{array}{l}\text { Dose } \\
\text { intensificati }\end{array}$ & $\begin{array}{l}85.2 \pm 5.0 \\
\text { ion }\end{array}$ & NA & $0.6(0.3-1.4)$ & 0.254 & $83.1 \pm 5.8$ & NA & $1.7(0.5-6.4)$ & 0.405 & $89.1 \pm 4.1$ & NA & $2.1(0.4-10.2)$ & 0.364 \\
\hline
\end{tabular}

OS: Overall survival; DFS: disease-free survival; LC: locoregional control; Plafur: cisplatin and 5-fluorouracil; Tomox: raltitrexed and oxaliplatin; Capeox: capecitabine and oxaliplatin; NA: not available; CRT: chemoradiotherapy; SE: standard error. Bold values show significance.

Local failure was reported in 25 patients and was perianastomotic in 22, pre-sacral in two and pelvic in one; distant metastasis occurred in 55 patients and eight patients had both local and distant progression.

\section{Discussion}

The purpose of this retrospective study was to evaluate pCR and long-term outcomes in patients with stage II/III rectal cancer treated with different long-course CRT and TME, with fluoropyrimidine chemotherapy and standard doses of 45-50 Gy, or with an intensification of drugs as cisplatin or oxaliplatin with or without raltitrexed, or with a dose intensification up to $55 \mathrm{~Gy}$.

The locoregional recurrence rate of LARC is about $20 \%$, even with TME. Neoadjuvant CRT is able to improve local control, resectability and $\mathrm{pCR}$ rates, as well as to reduce pathological stage $(3,4)$ (Table V). Capecitabine as a single preoperative concomitant agent was reported to lead to similar downstaging and pCR rates to 5-FU in phase II clinical trials $(5,6)$, but without statistical differences of OS, DFS and local recurrence rates between capecitabine and 5-FU, resulting instead in an improved pCR rate $(14 \% v s .5 \%, p=0.009)$ in the capecitabine arm. This suggested that capecitabine can replace 5-FU in neoadjuvant concomitant chemotherapy for locally advanced rectal cancer (7) (Table V).
The importance of tumor regression assessment in patients with LARC and its relationship with favorable long-term outcomes have been widely reported. Patients with no or few residual cancer cells (TRG1-2) in the pathological specimen after preoperative CRT had improved LC, DFS, and OS, independently of their initial clinical Tand N-stage.

In an Italian retrospective analysis, with 144 patients treated with preoperative CRT for LARC, a TRG1 rate of $19 \%$ was reported, with LC, DFS, and OS rates of $87 \%, 67 \%$ and $74 \%$, respectively (18). In the same way, a retrospective multicenter analysis collecting 566 patients with ypCR rate reported predictive favorable outcomes: 5-Year OS of $90 \%$, DFS of $85 \%$, cancer-specific survival rates of $94 \%$, distant metastases in 49 patients $(8.9 \%)$ and locoregional recurrence in seven patients $(1.6 \%)(19)$.

Rodel and colleagues assessed the impact of TRG, according to the Dworak classification, as a prognostic factor in 385 patients treated within the preoperative CRT arm of the CAO/ARO/AIO-94 trial. They reported TRG 4, 3, 2, 1, 0 rates of $10.4 \%, 52.2 \%, 13.8 \%, 15.3 \%$, and $8.3 \%$ of patients, and complete (TRG4) and intermediate pathologicaI response (TRG2-3) suggested improved DFS after preoperative CRT (20). Based on these and other results (2022), the pCR rate after CRT in LARC can be considered a surrogate endpoint for DFS and OS. 
in vivo $34: 1223-1233(2020)$

Table V. Pathological complete response rate and clinical outcomes in randomized studies of preoperative chemoradiotherapy for rectal cancer.

\begin{tabular}{|c|c|c|c|c|c|c|c|c|c|c|}
\hline $\begin{array}{l}\text { Authors and } \\
\text { years (Ref) }\end{array}$ & Patients, $\mathrm{n}$ & $\begin{array}{l}\text { Concomitant } \\
\text { CT drug }\end{array}$ & $\mathrm{pCR}(\%)$ & $p$-Value & $\begin{array}{l}5 \text {-Year } \\
\text { OS (\%) }\end{array}$ & $p$-Value & $\begin{array}{l}\text { 5-Year } \\
\text { DFS (\%) }\end{array}$ & $p$-Value & $\begin{array}{l}\text { 5-Year } \\
\text { LR }(\%)\end{array}$ & $p$-Value \\
\hline Bosset et al. & 506 & RT alone & 5.3 & & 64.8 & & 52.2 & & 17.1 & \\
\hline $2006(3)$ & 505 & $5-\mathrm{FU}$ & 14 & 0.005 & 65.8 & 0.84 & 58.2 & 0.12 & 7.6 & 0.002 \\
\hline Gerard et al. & 367 & RT alone & 3.6 & & 67.9 & & 55.5 & & 13.4 & \\
\hline 2006 (4) & 375 & $5-\mathrm{FU}$ & 11.4 & 0.001 & 67.4 & 0.68 & 59.4 & 0.68 & 6.67 & 0.004 \\
\hline Hofheinz et al. & 197 & Capecitabine & 14 & & 76 & & 68 & & 6 & \\
\hline $2012(7)$ & 195 & $5-\mathrm{FU}$ & 5 & 0.009 & 67 & 0.0004 & 54 & 0.35 & 7 & 0.67 \\
\hline Gerard et al. & 299 & Capecitabine (Cap45) & 13.9 & & $87.6^{*}$ & & $67.9 *$ & & $6.1^{*}$ & \\
\hline $2010(30)$ & 299 & $\begin{array}{c}\text { Capecitabine+ } \\
\text { oxaliplatin (Capox50) }\end{array}$ & 19.2 & 0.09 & $88.3 *$ & & $72.7 *$ & & $4.4^{*}$ & \\
\hline Rodel et al. & 613 & $5-\mathrm{FU}$ & 13 & & $88^{*}$ & & $71.2 *$ & & $4.6^{*}$ & \\
\hline $2015(31)$ & 623 & 5-FU+oxaliplatin & 17 & 0.031 & $88.7 *$ & & $75.9 *$ & 0.03 & $2.9^{*}$ & \\
\hline Valentini et al. & 280 & Capecitabine +55 Gy & 24.4 & & 80.4 & & 74.7 & & 7.4 & \\
\hline 2019 (32) & 254 & $\begin{array}{c}\text { Capecitabine+ } \\
\text { oxaliplatin+50.4 Gy }\end{array}$ & 23.8 & & 85.5 & 0.155 & 73.8 & 0.444 & 6.8 & \\
\hline Current study & 322 & Different CT drugs & 26.7 & & 82.5 & & 81.2 & & 6.9 & \\
\hline
\end{tabular}

CT: Chemotherapy; pCR: pathological complete response; OS: overall survival; DFS: disease-free survival; LR: locoregional relapse; RT: radiotherapy; 5-FU: 5-fluoropyrimidine. *3-Year data. Bold values show significance.

In a pooled analysis conducted by Maas et al. on 3,105 included patients, pCR was reported in 484, with 5-year DFS of $83.3 \%$ (95\% confidence intervaI $=78.8-87.0 \%)$ for patients with pCR (61/419 patients had disease recurrence) and of $65.6 \%(63.6-68.0 \%)$ for those without pCR (747/2263; hazard ratio $=0.44,95 \%$ confidence intervaI $=0.34-0.57$; $p<0.0001)$.The authors concluded that patients with pCR had a prognostically favorable biological tumor profile that significantly increased the probability of DFS (23).

Aiming to improve pCR as well as clinical outcomes, multidrug intensification and dose escalation have been largely investigated (Table V). 5-FU and raltitrexed combined with cisplatin or oxaliplatin and preoperative RT had a safe and effective profile, with high tumor down-staging and $\mathrm{pCR}$ rates, in several phase I-II studies (11, 24-26).

A randomized multicenter Italian trial, with 164 patients, reported an overall pCR rate of $30 \%$ with a greater rate of TRG1-2 in the Tomox-RT arm compared to the Plafur arm (51.9\% vs. $41 \%, p=0.162)$, and a greater rate of ypT0 and significant ypT downstaging $(p=0.035)$, even though there was greater acute grade 3 or more toxicity in the Tomox-RT $\operatorname{arm}(12)$.

Oxaliplatin plus fluoropyrimidine-based chemotherapy resulted in an improved pCR rate (range $=11-42 \%$ ) in several phase II and III studies, but at the expense of grade 3 or more adverse toxicity without improving clinical outcomes or pCR (27-31).

The German CAO/ARO/AIO-04 phase III trial showed a statistically significant improvement in $\mathrm{pCR}$ rate $(13 \% \mathrm{vs}$. $17 \%, p=0.038)$ and 3-year DFS (75.9\% vs. $71.2 \%, p=0.03)$ with the addition of oxaliplatin to 5-FU-based RT (31), although these differences were correlated, according to some author opinions, to the different schedules of 5-FU between the arms.

A multicentric randomized controlled trial was conducted by Valentini et al., investigating two different intensification regimens of preoperative CRT, on 534 patients, 280 treated with capecitabine and a boost dose intensification to $55 \mathrm{~Gy}$, and 254 patients treated with capecitabine and oxaliplatin and $50.4 \mathrm{~Gy}$. The TRG1-2 rates were $61.7 \%$ and $52.3 \%$ respectively ( $p=0.039)$ (32).

Our analyses showed a high pCR rate (TRG1-2: 41.8\%), with a TRG1-2 of $59.4 \%$ in the dose intensification group (EQD2 of $57.5 \mathrm{~Gy}$ ), similar to that of $61.7 \%$ obtained in the capecitabine arm in the INTERACT trial (32). Furthermore, our study found a statistically significant difference ( $p=0.046$ ) comparing TRG1-2 rates in the fluoropyrimidine group with standard dose of $50 \mathrm{~Gy}$ (42.2\%) compared to the dose intensification group (59.4\%) administered a total dose of $57.5 \mathrm{~Gy}$ (EQD2). Intensification seems to be attractive in improving clinical outcomes. In contrast, no statistically significant differences were found in clinical outcomes of OS, DFS and LC. In regard to acute and late toxicities, we did not find worse data in the dose intensification group compared to chemotherapy intensification regiments.

A dose-response relationship was confirmed by Burbach et al. in a meta-analysis on 18 trials of patients with LARC (33), reporting an improvement of pCR rate up to $20 \%$ delivering doses of $>6,000 \mathrm{cGy}$, with acceptable early toxicities. Similar results of dose-response relationships were reported by Appelt et al. in 222 patients treated with doses in the range of 50.4-70 Gy (34). 
The ability to predict circumferential resection margin involvement using MRI and its correlation with long-term outcomes were also investigated in literature (35). Unfortunately, our study was not able to report these data because of the small number of patients with circumferential resection margin involvement, previously staged by MRI.

Finally, with respect to the relationship between tumor parameters and long-term outcomes, a greater distance from the anorectal ring was reported as a favorable prognostic factor for DFS in the univariate ( $p=0.037$ ) analyses in our study (Table IV).

In conclusion, neoadjuvant long-course CRT in stage II/III rectal cancer resulted in favorable long-term oncological outcomes, with high pCR rate, tumor and nodal status downstaging, and acceptable toxicity. Dose escalation up to $55 \mathrm{~Gy}$ associated with fluoropyrimidine led to a significantly higher TRG1-2 rate of $59.4 \%$ ( $p=0.046)$ compared to standard doses of $50 \mathrm{~Gy}$ with fluoropyrimidine. Moreover, tumor response as TRG1-2 was associated with statistically higher rates of 5- and 10-year OS ( $p=0.001)$ and DFS $(p=0.014)$. In our retrospective study, the superior efficacy of dose escalation on major pathological outcome was demonstrated compared to standard dose or multidrug intensification.

\section{Conflicts of Interest}

The Authors report no conflicts of interest.

\section{Authors' Contributions}

MDT, CR, LC, AA, MT and DG designed and coordinate the study and the analysis. CR, AA, VB, SDS, FP collected the data. MDT, RC, AC, DA, MB, GS, LM reviewed and approved data selection. MDT, CR, LC, MM performed main data analysis and provided pictures elaboration. MM and MDN performed statistical data analysis. MDT, CR, LC drafted the article. MT, PI, PDS, GP, NDB, DG critically revised the study and the article. All Authors reviewed and approved the final article.

\section{References}

1 Kapiteijn E, Marijnen CA, Nagtegaal ID, Putter H, Steup WH, Wiggers T, Rutten HJ, Pahlman L, Glimelius B, van Krieken JH, Leer JW, van de Velde CJ; Dutch Colorectal Cancer Group: Preoperative radiotherapy combined with total mesorectal excision for resectable rectal cancer. N Engl J Med 345: 638646, 2001. PMID: 11547717. DOI: 0.1056/NEJMoa010580

2 Sauer R, Becker H, Hohenberger W, Rödel C, Wittekind C, Fietkau R, Martus P, Tschmelitsch J, Hager E, Hess CF, Karstens JH, Liersch T, Schmidberger H, Raab R; German Rectal Cancer Study Group: Preoperative versus postoperative chemoradiotherapy for rectal cancer. N Engl J Med 351: 1731-1740, 2004. PMID: 15496622. DOI: 10.1056/NEJMoa040694

3 Bosset JF, Collette L, Calais G, Mineur L, Maingon P, RadosevicJelic L, Daban A, Bardet E, Beny A, Ollier JC; EORTC Radiotherapy Group Trial 22921: Chemotherapy with preoperative radiotherapy in rectal cancer. N Engl J Med 355: 1114-1123, 2006. PMID: 16971718. DOI: 10.1056/NEJMoa060829
4 Gérard JP, Conroy T, Bonnetain F, Bouché O, Chapet O, ClosonDejardin MT, Untereiner M, Leduc B, Francois E, Maurel J, Seitz JF, Buecher B, Mackiewicz R, Ducreux M and Bedenne L: Preoperative radiotherapy with or without concurrent fluorouracil and leucovorin in T3-4 rectal cancers: Results of FFCD 9203. J Clin Oncol 24: 4620-4625, 2006. PMID: 17008704. DOI: $10.1200 / J C O .2006 .06 .7629$

5 Dupuis O, Vie B, Lledo G, Hennequin C, Noirclerc M, Bennamoun $\mathrm{M}$ and Jacob JH: Preoperative treatment combining capecitabine with radiation therapy in rectal cancer: A GERCOR Phase II Study. Oncology 73: 169-176, 2007. PMID: 18418009. DOI: $10.1159 / 000127383$

6 Desai SP, El-Rayes BF, Ben-Josef E, Greenson JK, Knol JA, Huang EH, Griffith KA, Philip PA, McGinn CJ and Zalupski MM: A phase II study of preoperative capecitabine and radiation therapy in patients with rectal cancer. Am J Clin Oncol 30: 340-345, 2007. PMID: 17762432. DOI: 10.1097/COC.0b013e318033ed63

7 Hofheinz RD, Wenz F, Post S, Matzdorff A, Laechelt S, Hartmann JT, Müller L, Link H, Moehler M, Kettner E, Fritz E, Hieber U, Lindemann HW, Grunewald M, Kremers S, Constantin C, Hipp M, Hartung G, Gencer D, Kienle P, Burkholder I and Hochhaus A: Chemoradiotherapy with capecitabine versus fluorouracil for locally advanced rectal cancer: A randomised, multicentre, noninferiority, phase 3 trial. Lancet Oncol 13: 579-588, 2012. PMID: 22503032. DOI: 10.1016/S1470-2045(12)70116-X

8 UICC International Union Against Cancer: TNM Classification of Malignant Tumours. Fifth Edition Berlin: Springer-Verlag; 1997.

9 Roels S, Duthoy W, Haustermans K, Penninckx F, Vandecaveye V, Boterberg T, De Neve W: Definition and delineation of the clinical target volume for rectal cancer. Int J Radiat Oncol Biol Phys 65: 1129-1142, 2006. PMID: 16750329. DOI: 10.1016/j. ijrobp.2006.02.050

10 International Commission on Radiation Units and Measurements: ICRU Report 62. Prescribing, recording and reporting photon beam therapy (supplement to ICRU report 50). Bethesda, 1999.

11 Gambacorta MA, Valentini V, Coco C, Morganti AG, Smaniotto D, Miccichè F, Mantini G, Barbaro B, Garcia-Vargas JE, Magistrelli P, Picciocchi A and Cellini N: Chemoradiation with raltitrexed and oxaliplatin in preoperative treatment of stage IIIII resectable rectal cancer: Phase I and II studies. Int J Radiat Oncol Biol Phys 60: 139-148, 2004. PMID: 15337549. DOI: 10.1016/j.jijrobp.2004.01.051

12 Valentini V, Coco C, Minsky BD, Gambacorta MA, Cosimelli M, Bellavita R, Morganti AG, La Torre G, Trodella L, Genovesi D, Portaluri M, Maurizi-Enrici R, Barbera F, Maranzano E and Lupattelli M: Randomized, multicentre, phase IIB study of preoperative chemoradiotherapy in $\mathrm{T} 3$ mid-distal rectal cancer: raltitrexed+oxaliplatin+radiotherapy versus cisplatin +5 fluorouracil+radiotherapy. Int J Radiat Oncol Biol Phys 70: 403412, 2008. PMID: 17919844. DOI: 10.1016/j.ijrobp.2007.06.025

13 Gambacorta MA, Valentini V, Coco C, Manno A, Doglietto GB, Ratto C, Cosimelli M, Miccichè F, Maurizi F, Tagliaferri L, Mantini G, Balducci M, La Torre G, Barbaro B and Picciocchi A: Sphincter preservation in four consecutive phase II studies of preoperative chemoradiation: Analysis on 247 T3 rectal cancer patients. Tumor 93: 160-169, 2007. PMID: 17557563.

14 Mandard AM, Dalibard F, Mandard JC, Marnay J, Henry-Amar M, Petiot JF, Roussel A, Jacob JH, Segol P and Samama G: Pathological assessment of tumor regression after preoperative chemoradiotherapy 
of esophageal carcinoma: Clinicopathologic correlations. Cancer 73: 2680-2686, 1994. PMID: 8194005. DOI: 10.1002/10970142(19940601)73: 11<2680::aid-cncr2820731105>3.0.co;2-c

15 Cox JD, Stetz J and Pajak TF: Toxicity criteria of the Radiation Therapy Oncology Group (RTOG) and the European Organization for Research and Treatment of Cancer (EORTC). Int J Radiat Oncol Biol Phys 31: 1341-1646, 1995. PMID: 7713792. DOI: 10.1016/0360-3016(95)00060-C

16 RTOG/EORTC. RTOG/EORTC Late Radiation Morbidity Scoring Scheme, 2006.

17 Cox DR: Regression models and life-tables. J R Stat Soc Ser B34: 187-220, 1972.

18 Vecchio FM, Valentini V, Minsky BD, Padula GD, Venkatraman ES, Balducci M, Miccichè F, Ricci R, Morganti AG, Gambacorta MA, Maurizi F and Coco C: The relationship of pathologic tumor regression grade (TRG) and outcomes after preoperative therapy in rectal cancer. Int $\mathrm{J}$ Radiat Oncol Biol Phys 62: 752-760, 2005. PMID: 15936556. DOI: 10.1016/j.ijrobp.2004.11.017

19 Capirci C, Valentini V, Cionini L, De Paoli A, Rodel C, GlynneJones R, Coco C, Romano M, Mantello G, Palazzi S, Mattia FO, Friso ML, Genovesi D, Vidali C, Gambacorta MA, Buffoli A, Lupattelli M, Favretto MS and La Torre G: Prognostic value of pathologic complete response after neoadjuvant therapy in locally advanced rectal cancer: long-term analysis of 566 ypCR patients. Int J Radiat Oncol Biol Phys 72: 99-107, 2008. PMID: 18407433. DOI: 10.1016/j.ijrobp.2007.12.019

20 Rodel C, Martus P, Papadoupolos T, Füzesi L, Klimpfinger M, Fietkau R, Liersch T, Hohenberger W, Raab R, Sauer R and Wittekind C: Prognostic significance of tumor regression after preoperative chemoradiotherapy for rectal cancer. J Clin Oncol 23: 8688-8696, 2005. PMID: 16246976. DOI: 10.1200/JCO. 2005.02.1329

21 Bouzourene H, Bosman FT, Seelentag W, Matter M and Coucke $\mathrm{P}$ : Importance of tumor regression assessment in predicting the outcome in patients with locally advanced rectal carcinoma who are treated with preoperative radiotherapy. Cancer 94: 11211130, 2002. PMID: 11920483.

22 Vironen J, Juhola M, Kairaluoma M, Jantunen I and Kellokumpu I: Tumour regression grading in the evaluation of tumour response after different preoperative radiotherapy treatments for rectal carcinoma. Int J Colorectal Dis 20: 440-445, 2005. PMID: 15856263. DOI: 10.1007/s00384-004-0733-y

23 Maas M, Nelemans PJ, Valentini V, Das P, Rödel C, Kuo LJ, Calvo FA, García-Aguilar J, Glynne-Jones R, Haustermans K, Mohiuddin M, Pucciarelli S, Small W Jr, Suárez J, Theodoropoulos G, Biondo S, Beets-Tan RG and Beets GL: Long-term outcome in patients with a pathological complete response after chemoradiation for rectal cancer: A pooled analysis of individual patient data. Lancet Oncol 11: 835-844, 2010. PMID: 20692872. DOI: 10.1016/S1470-2045(10)70172-8

24 Martoni A, Mini E, Pinto C, Gentile AL, Nobili S, Dentico P, Marino A, Scicolone S, Angelelli B and Mazzei T: Oxaliplatin plus raltitrexed in the treatment of patients with advanced colorectal cancer: A phase II study. Anticancer Res 23: 687-691, 2003. PMID: 12680168.

25 Caravatta L, Padula GD, Picardi V, Macchia G, Deodato F, Massaccesi M, Sofo L, Pacelli F, Rotondi F, Cecere G, Sallustio G, Di Lullo L, Piscopo A, Mignogna S, Bonomo P, Cellini N, Valentini $\mathrm{V}$ and Morganti AG: Concomitant boost radiotherapy and multidrug chemotherapy in the neoadjuvant treatment of locally advanced rectal cancer: results of a phase II study. Acta Oncol 50: 1151-1157, 2011. PMID: 21851185. DOI: 10.3109/ 0284186X.2011.582880

26 Caravatta L, Picardi V, Tambaro R, Padula GD, Macchia G, Deodato F, Massaccesi M, Pacelli F, Berardi S, Ridolfini MP, Di Filippo L, Fabrizio G, Ingrosso M, Cellini N, Valentini V and Morganti AG: Neoadjuvant accelerated concomitant boost radiotherapy and multidrug chemotherapy in locally advanced rectal cancer: a dose-escalation study. Am J Clin Oncol 35: 424-431, 2012. PMID: 21555930. DOI: 10.1097/COC.0b013e31821a5844

27 Rödel C and Sauer R: Integration of novel agents into combinedmodality treatment for rectal cancer patients. Strahlenther Onkol 183: 227-235, 2007. PMID: 17497093. DOI: 10.1007/s00066007-9000-9

28 Aschele C, Cionini L, Lonardi S, Pinto C, Cordio S, Rosati G, Artale S, Tagliagambe A, Ambrosini G, Rosetti P, Bonetti A, Negru ME, Tronconi MC, Luppi G, Silvano G, Corsi DC, Bochicchio AM, Chiaulon G, Gallo M and Boni L: Primary tumor response to preoperative chemoradiation with or without oxaliplatin in locally advanced rectal cancer: Pathologic results of the STAR-01 randomized phase III trial. J Clin Oncol 29: 2773-2780, 2011. PMID: 21606427. DOI: 10.1200/JCO. 2010.34.4911

29 Allegra CJ, Yothers G, O'Connell MJ, Beart RW, Wozniak TF, Pitot HC, Shields AF, Landry JC, Ryan DP, Arora A, Evans LS, Bahary N, Soori G, Eakle JF, Robertson JM, Moore DF Jr, Mullane MR, Marchello BT, Ward PJ, Sharif S, Roh MS and Wolmark N: Neoadjuvant 5-FU or capecitabine plus radiation with or without oxaliplatin in rectal cancer patients: A phase III randomized clinical trial. J Natl Cancer Inst 11: 107-115, 2015. PMID: 26374429. DOI: 10.1093/jnci/djv248

30 Gérard JP, Azria D, Gourgou-Bourgade S, Martel-Laffay I, Hennequin C, Etienne PL, Vendrely V, François E, de La Roche G, Bouché O, Mirabel X, Denis B, Mineur L, Berdah JF, Mahé MA, Bécouarn Y, Dupuis O, Lledo G, MontotoGrillot $\mathrm{C}$ and Conroy $\mathrm{T}$ : Comparison of two neoadjuvant chemoradiotherapy regimens for locally advanced rectal cancer: Results of the phase III trial ACCORD 12/0405Prodige 2. J Clin Oncol 28: 1638-1644, 2010. PMID: 20194850. DOI: $10.1200 / J C O .2009 .25 .8376$

31 Rödel C, Graeven U, Fietkau R, Hohenberger W, Hothorn T, Arnold D, Hofheinz RD, Ghadimi M, Wolff HA, LangWelzenbach M, Raab HR, Wittekind C, Ströbel P, Staib L, Wilhelm M, Grabenbauer GG, Hoffmanns H, Lindemann F, Schlenska-Lange A, Folprecht G, Sauer R, Liersch T; German Rectal Cancer Study Group: Oxaliplatin added to fluorouracilbased preoperative chemoradiotherapy and postoperative chemotherapy of locally advanced rectal cancer (the German CAO/ARO/AIO-04 study): Final results of the multicentre, openlabel, randomised, phase 3 trial. Lancet Oncol 16: 979-689, 2015. PMID: 26189067. DOI: 10.1016/S1470-2045(15)00159-X

32 Valentini V, Gambacorta MA, Cellini F, Aristei C, Coco C, Barbaro B, Alfieri S, D'Ugo D, Persiani R, Deodato F, Crucitti A, Lupattelli M, Mantello G, Navarria F, Belluco C, Buonadonna A, Boso C, Lonardi S, Caravatta L, Barba MC, Vecchio FM, Maranzano E, Genovesi D, Doglietto GB, Morganti AG, La Torre G, Pucciarelli S and De Paoli A: The INTERACT Trial: Long-term results of a randomised trial on preoperative capecitabine-based radiochemotherapy intensified 
by concomitant boost or oxaliplatin, for cT2 (distal)-cT3 rectal cancer. Radiother Oncol 134: 110-118, 2019. PMID: 31005204. DOI: 10.1016/j.radonc .2018 .11 .023

33 Burbach JP, den Harder AM, Intven M, van Vulpen M, Verkooijen HM and Reerink O: Impact of radiotherapy boost on pathological complete response in patients with locally advanced rectal cancer: A systematic review and meta-analysis. Radiother Oncol 113: 1-9, 2014. PMID: 25281582. DOI: 10.1016/j. radonc.2014.08.035

34 Appelt AL, Pløen J, Vogelius IR, Bentzen SM and Jakobsen A: Radiation dose-response model for locally advanced rectal cancer after preoperative chemoradiation therapy. Int J Radiat Oncol Biol Phys 85: 74-80, 2013. PMID: 22763027. DOI: 10.1016/j.ijrobp.2012.05.017
35 Taylor FG, Quirke P, Heald RJ, Moran BJ, Blomqvist L, Swift IR, Sebag-Montefiore D, Tekkis P, Brown G; Magnetic Resonance Imaging in Rectal Cancer European Equivalence Study Study Group: Preoperative magnetic resonance imaging assessment of circumferential resection margin predicts diseasefree survival and local recurrence: 5-Year follow-up results of the MERCURY study. J Clin Oncol 32: 34-43, 2014. PMID: 24276776. DOI: $10.1200 /$ JCO.2012.45.3258

Received February 21, 2020

Revised March 10, 2020

Accepted March 11, 2020 